\title{
ERRATUM
}

\section{Cytogenetic effect of low dose $\gamma$-radiation in Hordeum vulgare seedlings: non-linear dose-effect relationship}

\author{
Stanislav A. Geras'kin · Alla A. Oudalova \\ Jin Kyu Kim • Vladimir G. Dikarev • \\ Nina S. Dikareva
}

Published online: 6 February 2007

(C) Springer-Verlag 2007

Erratum to: Radiat Environ Biophys

DOI 10.1007/00411-006-0082-z

In formula 2 for the PL model, a symbol $D$ is missing in the second row. The correct formula should read as follows:

$F(D)= \begin{cases}a_{1}+b_{1} D_{1}, & D<D_{1} \\ a_{2}, & D_{1}<D<D_{2} \\ a_{3}+b_{3} D_{1}, & D>D_{2}\end{cases}$

In reference 21, the title of Constantin and Nilan's article should read "A report ...", not "qA report ...".

The online version of the original article can be found at http://dx.doi.org/10.1007/00411-006-0082-z.

S. A. Geras'kin $(\bowtie) \cdot$ A. A. Oudalova ·

V. G. Dikarev · N. S. Dikareva

Russian Institute of Agricultural Radiology and Agroecology, Kievskoe shosse109 km, 249030 Obninsk, Russia

e-mail: stgeraskin@gmail.com

J. K. Kim

Korea Atomic Energy Research Institute,

150 Deokjin-dong, Yuseong-gu,

Daejeon 305-353, South Korea 